\title{
Experimental study of tsunami-induced scour around a monopile foundation
}

Larsen, Bjarke Eltard; Kærgaard Arbøll, Lasse ; Kristoffersen, Sarah Frigaard; Carstensen, Stefan; Fuhrman, David R.

Published in:

Coastal Engineering

Link to article, DOI:

10.1016/j.coastaleng.2018.04.007

Publication date:

2018

Document Version

Peer reviewed version

Link back to DTU Orbit

Citation $(A P A)$ :

Larsen, B. E., Kærgaard Arbøll, L., Kristoffersen, S. F., Carstensen, S., \& Fuhrman, D. R. (2018). Experimental study of tsunami-induced scour around a monopile foundation. Coastal Engineering, 138, 9-21.

https://doi.org/10.1016/j.coastaleng.2018.04.007

\section{General rights}

Copyright and moral rights for the publications made accessible in the public portal are retained by the authors and/or other copyright owners and it is a condition of accessing publications that users recognise and abide by the legal requirements associated with these rights.

- Users may download and print one copy of any publication from the public portal for the purpose of private study or research.

- You may not further distribute the material or use it for any profit-making activity or commercial gain

- You may freely distribute the URL identifying the publication in the public portal

If you believe that this document breaches copyright please contact us providing details, and we will remove access to the work immediately and investigate your claim. 


\title{
Experimental study of tsunami-induced scour around a monopile foundation
}

\author{
Bjarke Eltard Larsen $^{\mathrm{a}, *}$, Lasse Kærgaard Arbøll ${ }^{\mathrm{a}}$, Sarah Frigaard Kristoffersen ${ }^{\mathrm{a}}$, Stefan Carstensen $^{\mathrm{a}}$, David R. Fuhrman ${ }^{\mathrm{a}}$ \\ ${ }^{a}$ Technical University of Denmark, Department of Mechanical Engineering, DK-2800 Kgs. Lyngby, Denmark
}

\begin{abstract}
This paper presents an experimental study of the tsunami-induced scour process around a monopile foundation, representative of those commonly used for offshore wind farms. The scour process is studied by subjecting the monopile to a time varying current, which enables a properly down-scaled experiment from the boundary layer and scour perspective. It is shown how the scaled experiments corresponds to real life idealized tsunami cases with periods ranging from 10 to 40 min. It is then shown that the boundary layers of the model tsunami are well described by recently developed empirical relations for tsunami boundary layers. By subjecting the monopile to several successive tsunami waves the scour process is shown to occur in a stepwise cumulative fashion, with the final equilibrium scour depth tending to the depth limited steady current limit. It is shown that the entire scour development can reasonably be predicted by a recently developed simple engineering model. Finally, the experimental results are compared to a fully coupled hydrodynamic and morphologic CFD model and a good correspondence is obtained.
\end{abstract}

Keywords: Tsunamis, Boundary layers, Scour, Morphology, Monopiles, Computational Fluid Dynamics

\section{Introduction}

Tsunamis are long waves, typically having periods the order of minutes to hours, that are commonly caused by sudden motions of the bed e.g. due to landslides or earthquakes. Tsunami research has been carried out using many different approaches. Tsunami deposits have been gathered to get an idea of prehistoric tsunamis, see. e.g. Dawson and Shi (2000) for an overview. Tsunamis have also been studied by conducting surveys and actual field measurements, see Lacy et al. (2012), Bricker et al. (2012), Kuriyama et al. (2014), Fu et al. (2013), Udo et al. (2016) and Jayaratne et al. (2016). A few analytical studies exists e.g. Madsen et al. (2008) and Yeh and Mason (2014). Numerically, most tsunami research has focused on solving the non-linear shallow water equations or simulating the tsunami with a Boussinesq model see e.g. Madsen and Fuhrman (2008), Fuhrman and Madsen (2009), Apotsos et al. (2011a), Apotsos et al. (2011c), Apotsos et al. (2011b), Cheng and Weiss (2013), Sugawara et al. (2014a), Sugawara et al. (2014b). Recently, more computationally heavy numerical studies have been performed by solving the ReynoldsAveraged-Navier-Stokes (RANS) equations by Douglas and Nistor (2015) and Jiang et al. (2015), or with the Smoothed Particle Hydrodynamics Method (SPH) by Wei et al. (2016). Experimentally, tsunamis have often been attempted to be studied using solitary waves. However, when scaled up, these waves resemble more wind wave than tsunami scales, as their flow durations are far too short, and their relevance to real-worldgeophysical tsunamis is questionable (see Madsen et al. (2008) and Chan and Liu (2012)). Schimmels et al. (2016) have suc-

\footnotetext{
${ }^{*}$ Corresponding author

Email address: bjelt@mek.dtu.dk (Bjarke Eltard Larsen )
}

ceed in producing properly-scaled tsunamis and the same experimental facility was used to study tsunami propagation by Sriram et al. (2016), where the feasibility of studying tsunami run-up was also discussed. Onshore tsunamis have also been studied as bores see. e.g. Lavictoire (2015) or Douglas and Nistor (2015). However, as noted by Sriram et al. (2016), the undular or breaking bores are just two realizations of tsunami run-up, and one cannot generalize a particular tsunami case, as even the same tsunami event can have very different manifestations at different locations. Also, when studying tsunamis as bores, scaling considerations are still important, as the duration of the experimental bore should be sufficiently long. As discussed by Schimmels et al. (2016), a typical full scale tsunami event with a duration of 1000 seconds, corresponds to $100 \mathrm{sec}-$ onds at model scale using a scaling factor of 100 using a standard Froude scaling approach. This is a much longer duration than most model-scale tsunami experiments.

Studies investigating tsunami-induced scour around coastal and offshore structures (the focus of the present work) are rather limited. From surveys, Wilson et al. (2012) studied the sediment scour and deposition within harbours in California as a result of the 2011 Tohoku tsunami. Experimentally, Chen et al. (2013) studied the tsunami-induced scour at coastal roadways. Also, Bricker et al. (2012) conducted a field study of scour depths measured on the landward side of seawalls and floodwalls, as well as beside a building foundation footing, from the 2011 Tohoku tsunami. Experimental investigations on the tsunami-induced scour specifically around monopiles are seemingly limited to those of Tonkin et al. (2003), who studied the scour promoted by incident solitary waves around a cylinder on a sloping beach, where the cylinder was mounted near the shoreline, Nakamura et al. (2008) who studied scour around a square pile induced by solitary and long waves, as well as by 
Shafiei et al. (2015) and Lavictoire (2015) who studied the boreinduced local scour around a circular structure. It is again emphasized that the temporal duration using solitary waves are far less than would be typical of model scale geophysical tsunamis.

While the behaviour and evolution of tsunami waves is indeed difficult to reproduce experimentally due to the long durations, the offshore near-bed processes can be studied by viewing the tsunami as a time varying current, which is justifiable provided that the Froude number is sufficiently small. This has been done by Williams and Fuhrman (2016), who simulated a series of tsunami-scale boundary layers, emphasizing that they are both current like and wave like. The boundary layers resemble steady currents due to their long duration. They also resemble waves, as they are unsteady and the boundary layer may not span the entire water depth. This assertion is likewise consistent with field measurements of Lacy et al. (2012). Larsen et al. (2017) simulated the tsunami-induced scour at model scale by also approximating the tsunami-induced flow as a time varying current within a CFD approach. They developed a procedure for properly scaling tsunami-induced scour and came up with a practical engineering model for predicting the scour development beneath successive tsunami waves.

The two afore mentioned studies approximating tsunamiinduced boundary layers and scour are both numerical in nature. However, representing a tsunami via a time varying current is also experimentally attractive, as it enables the study of offshore tsunami-induced boundary layers and scour to be performed using a pump-driven flow, rather than more traditional wave paddles. It can be noted that the scour process beneath a time varying current has also been studied previously by Link et al. (2017), though with the intent to study flood waveinduced scour around bridge piers. The present paper aims to extend knowledge on tsunami-induced scour around off-shore monopile foundations by studying the scour process induced by the pump-driven flow that would be expected beneath long properly-scaled tsunami waves. This approach also means that the effect of variation in pore pressure gradients on the scour process as described by Tonkin et al. (2003) and Nakamura et al. (2008) are not accounted for the current setup. This is reasonable if the monopile is standing off-shore and the Froude number is small. The paper also aims to strengthen the link to the practical engineering models developed in the purely numerical studies by Williams and Fuhrman (2016) and Larsen et al. (2017). The numerical models employed in these studies have therefore also been used in the present study to simulate the boundary layers and scour process of selected cases.

\section{Experimental methods and equipment}

The present experiments have been conducted within the hydraulics laboratory at DTU in a flume which is $35 \mathrm{~m}$ long, 2 $\mathrm{m}$ wide and $0.5 \mathrm{~m}$ deep. The flume has glass side walls, providing a good view of the flow and scour process. The water depth in all the experiments was $h=0.27 \mathrm{~m}$. A sand bed spanning $8 \mathrm{~m}$ was placed with its center at the center of the flume, and the sand had a grain size of $d_{50}=0.18 \mathrm{~mm}$. The sand bed spanned the entire width of the flume and the thickness of the bed was $0.15 \mathrm{~m}$, which ensured that the bottom of the flume was not reached during the scour process. A transparent circular pile made from an acrylic tube with an outer diameter $D=0.1 \mathrm{~m}$ was placed at the center of the sand bed. At the ends of the sand bed a slope of 1:8 was made of tiles $(0.4 \mathrm{~m}$ $\mathrm{x} 0.4 \mathrm{~m}$ ), in order to keep the sand in place. These tiles were covered by stones with sieve diameters ranging from $1.6 \mathrm{~cm}$ to $3.2 \mathrm{~cm}$, to create an even slope. A H33-1 Armfield micropropeller velocity meter was placed between the sidewall and the pile. Furthermore, the device was positioned far enough from the bed so it measured the free-stream velocity of the incoming flow. The lower limit of the measuring range of the H33-1 micropropeller is specified as $0.05 \mathrm{~m} / \mathrm{s}$. Velocities below this limit have therefore been omitted in the results. Figure 1 shows a schematic view of the test set-up including the location of the micropropeller and in Figure 2 an image of the set-up is shown. Finally, Figure 3 shows a close-up image of the micropropeller and monopile. The flow in the flume was created by a pump which could be controlled by sending in a time varying control signal. The initial program for controlling the pump was not optimal, and therefore an effort was made to improve the control signals. In what follows the signals produced with the initial control program will be referred to as Program 1, whereas signals produced with the improved method will be referred to as Program 2. The initial and final bed levels were measured with a laser distance meter (optoNCDT ILR 1182-30) mounted on a carriage with two degrees of freedom. Another laser distance meter recorded the position of the carriage in the stream-wise direction, while a draw-wire encoder (Kübler D5.3501.A221) recorded the transverse position. The output from the distance sensors were connected to a data acquisition system (NI-USB6218). Post processing of the point measurements gave the bed topology around the pile. The measurements of the temporal scour variation were performed using a GoPro Hero3+ camera. The camera was placed inside the cylinder along with a chart with equally spaced grid lines of $1 \mathrm{~cm}$. Figure 4 shows an example of the view from inside the monopile.

In Williams and Fuhrman (2016) three different realizations for idealized tsunami events were considered: a single (elongated soliton) wave, a so-called $\mathrm{N}$-wave and a sinusoidal wave. For this study a single wave was utilized as a representation of a tsunami, with the free stream velocity given by

$$
u_{0}=U_{m} \operatorname{sech}^{2}(\Omega t),
$$

where $u_{0}$ is the free stream velocity, $U_{m}$ is the maximum free stream velocity, $\Omega=2 \pi / T$ where $T$ can be interpreted as a characteristic period of motion corresponding to the time duration where the free stream flow exceeds $0.007 U_{m}$. It should be noted that, although solitary-like in shape, the period and velocity magnitude can be chosen independently, thus allowing their individual proper scaling. The single wave was chosen in part because a uni-directional velocity signal could be better controlled than an oscillating signal, and in part because it enabled the study of the scour process using a new generic signal. In contrast, Larsen et al. (2017) studied the tsunami-induced scour process by utilizing a sinusoidal flow as a generic tsunami sig- 


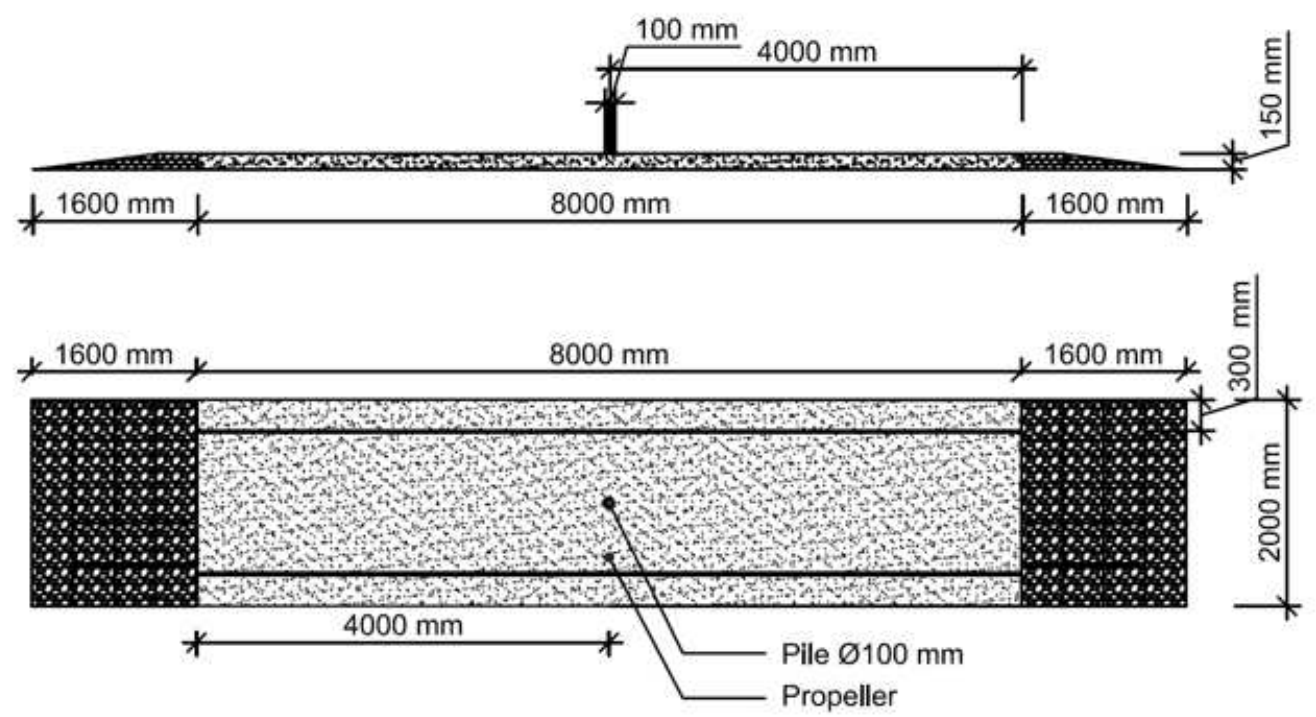

Figure 1: Schematic view of the test set-up. A pile with a outer diameter of $0.1 \mathrm{~m}$ is placed in the middle of a $8 \mathrm{~m}$ long, $2 \mathrm{~m}$ wide and $0.15 \mathrm{~m}$ deep sand bed. A $1: 8$ slope is placed at both ends of the sand bed.

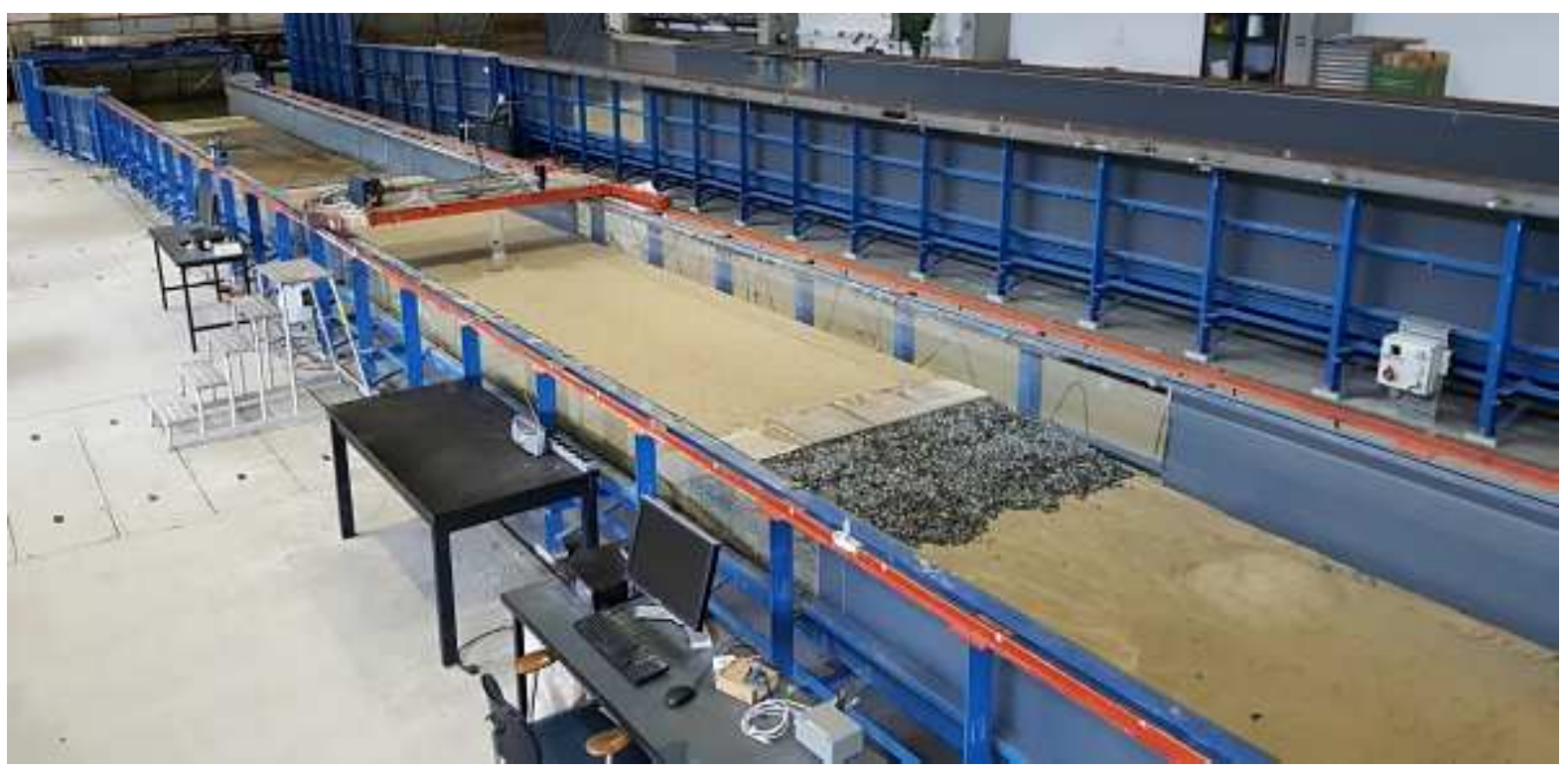

Figure 2: An image of the set-up in the flume. The carriage used when recording the bed topology is in this image over the upstream end of the sand bed. 


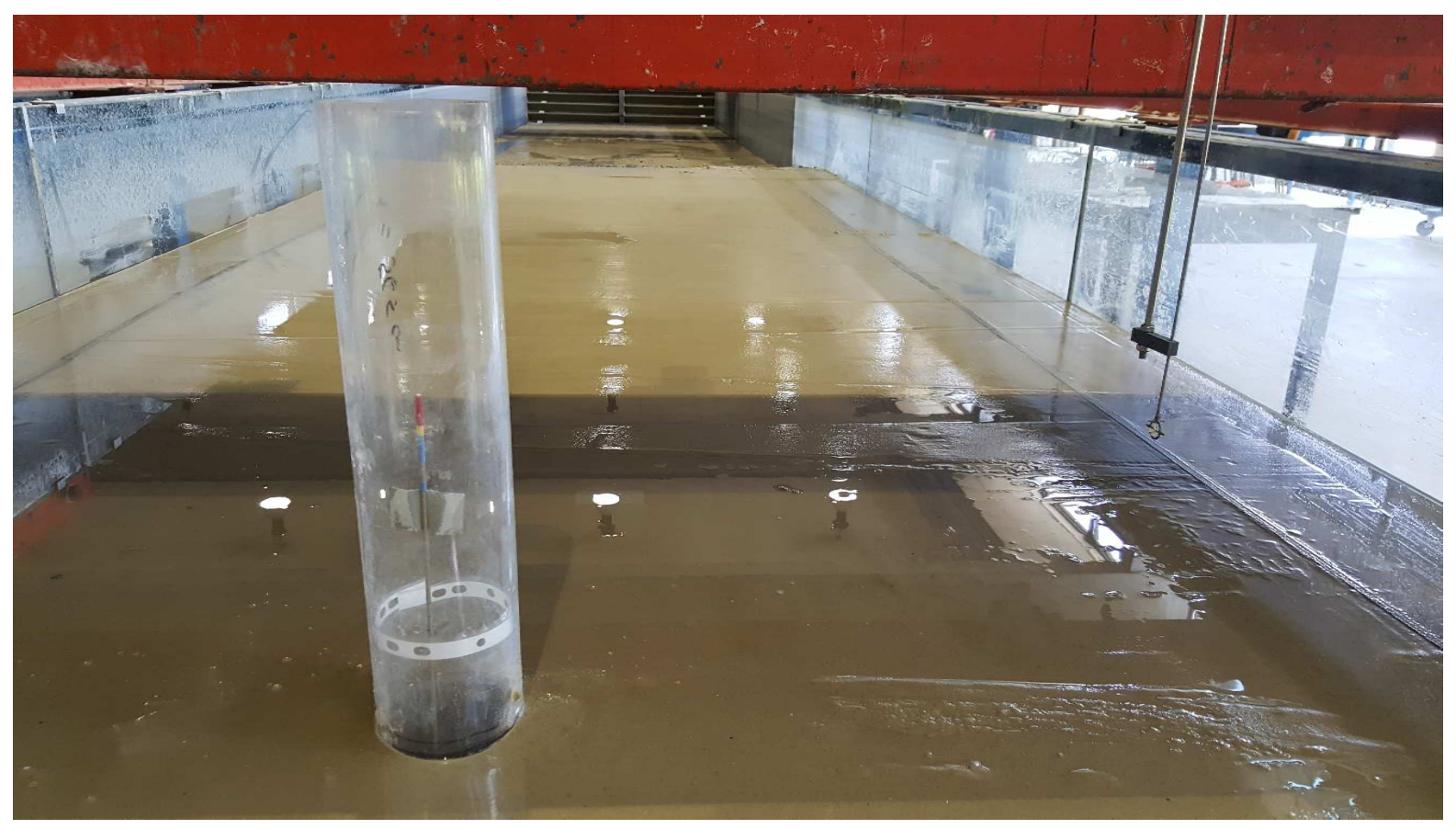

Figure 3: A close-up of the monopile and propeller.

Table 1: Dimensional and non-dimensional quantities for each case, where the boundary layer thickness $\delta$ is estimated as the minimum of that predicted from (2) and the water depth $h$. For Case 1-9 the mean, $\mu$, and standard deviation, $\sigma$, of the amplitude of the velocity $U_{m}$ is showed. The mean velocity is used as the reference value. The effective scouring fraction, $\psi$ is calculated from (16). Case 1-3 were generated using Program 1 and Case 4-12 were generated using Program 2.

\begin{tabular}{ccccccccc}
\hline Case & $T[\mathrm{~s}]$ & \multicolumn{2}{c}{$U_{m}[\mathrm{~m} / \mathrm{s}]$} & $S_{e} / D$ & $\delta / h$ & $\theta_{m}$ & $N_{\text {waves }}$ & $\psi$ \\
& \multicolumn{7}{c}{$\mu$} & $\sigma$ \\
\hline 1 & 177 & 0.32 & 0.011 & 0.76 & 0.52 & 0.07 & 89 & - \\
2 & 161 & 0.34 & 0.007 & 0.89 & 0.50 & 0.07 & 62 & - \\
3 & 146 & 0.40 & 0.020 & 0.89 & 0.53 & 0.10 & 66 & - \\
\hline 4 & 72 & 0.42 & 0.020 & 0.83 & 0.28 & 0.12 & 48 & 0.10 \\
5 & 79 & 0.45 & 0.023 & 0.87 & 0.33 & 0.13 & 44 & 0.09 \\
6 & 97 & 0.40 & 0.022 & 0.86 & 0.36 & 0.10 & 55 & 0.15 \\
7 & 123 & 0.45 & 0.014 & 1.00 & 0.50 & 0.13 & 58 & 0.12 \\
8 & 147 & 0.42 & 0.013 & 0.98 & 0.56 & 0.11 & 52 & 0.11 \\
9 & 479 & 0.42 & 0.008 & 1.08 & 1.00 & 0.09 & 40 & 0.07 \\
\hline 10 & 79 & 0.49 & - & - & 0.36 & 0.15 & - & - \\
11 & 123 & 0.51 & - & - & 0.56 & 0.15 & - & - \\
12 & 479 & 0.49 & - & - & 1.00 & 0.12 & - & - \\
\hline 13 & - & 0.41 & - & 1.23 & 1.00 & 0.12 & - & - \\
14 & - & 0.25 & - & 0.82 & 1.00 & 0.04 & - & -
\end{tabular}

nal.

Table 1 lists the maximum free stream velocity, the period, the non-dimensional equilibrium scour depth $\left(S_{e} / D\right)$, the boundary layer thickness to water depth ratio $(\delta / h)$ and the maximum Shields parameter $\left(\theta_{m}\right)$. Cases 1-9 are intended as tsunami scour experiments. Cases 10-12 are intended as pure tsunami boundary layer experiments. In these test the undisturbed velocity profile were measured by pitot tubes placed at varying distances from the bed. Finally, Cases 13-14 correspond to steady current scour measurements, which can be regarded as the infinite period limit. The boundary layer thickness is calculated utilizing expressions provided by Williams and
Fuhrman (2016). Specifically, for hydraulically smooth conditions they suggested:

$$
\frac{\delta}{a}=0.044 R e^{-0.07}
$$

where $a=U_{m} / \Omega$ is a characteristic length scale and $R e=$ $a U_{m} / v$ is the Reynolds number. The hydraulically smooth expression was used for all the model scale experiment calculations since $k_{s}^{+}=k_{s} U_{f} / v$ never exceeds 10 , where $U_{f}$ is the friction velocity and $v$ the kinematic viscosity. Alternatively, for hydraulically rough condition (used when calculating the full scale equivalents of the model scale experiments) they suggested:

$$
\frac{\delta}{a}=0.05\left(\frac{a}{k_{s}}\right)^{-0.11}
$$

where $k_{s}=2.5 d_{50}$ is Nikuradse's equivalent sand roughness. Furthermore, the Shields parameter was calculated by

$$
\theta_{m}=\frac{U_{f m}^{2}}{(s-1) g d_{50}}
$$

where $s=2.65$ is the relative density of the grains, $g$ is gravitational acceleration, and $U_{f m}$ is the maximum friction velocity calculated from

$$
U_{f m}=\sqrt{\frac{f_{w}}{2}} U_{m}
$$

where the friction factor is given by

$$
f_{w}=0.04 R e^{-0.16}
$$

and

$$
f_{w}=\exp \left(5.5\left({\frac{a}{k_{s}}}^{-0.16}-6.7\right)\right)
$$




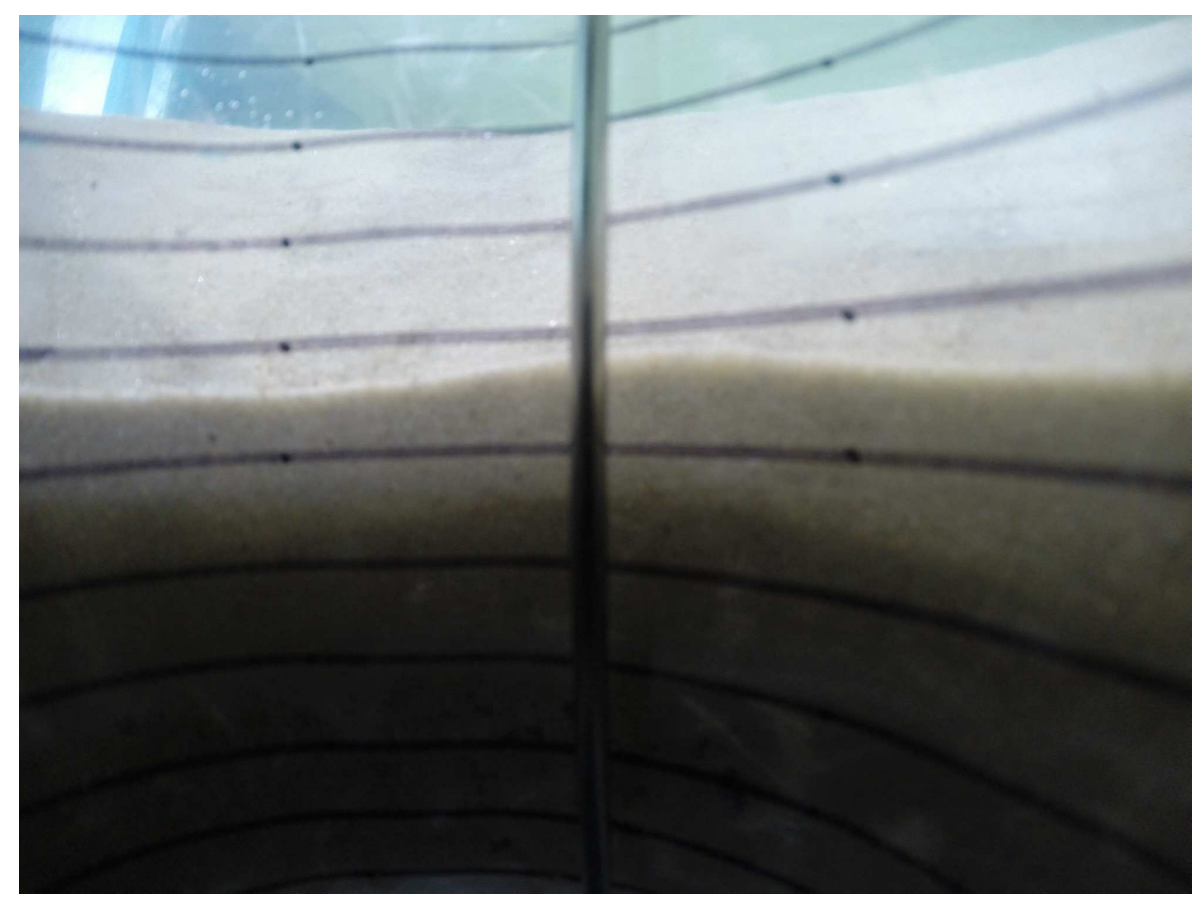

Figure 4: Image from inside the monopile.

for the hydraulically smooth and rough conditions, respectively. These friction factor expressions come from Fuhrman et al. (2013) and were shown by Williams and Fuhrman (2016) to give reasonable friction factor estimates for the simulated tsunami cases.

Due to the inability of the propeller to measure small velocities, the period of the incoming flow could not be determined directly. The period is therefore found by minimizing the error between the measured and the analytical velocity (see equation (1)) at $u_{0}>0.95 U_{m}$ for Case 1-3 and $u_{0}>0.8 U_{m}$ for Case 412. Figure 5 shows the measured free-stream velocity and the fit utilized for the period for 6 of the cases, as typical examples. It is readily apparent that the measured velocity variations fit better with the $\operatorname{sech}^{2}$ profile for Cases 6-9 than for Cases 2 and 3. This is due to the fact that Cases 1-3 utilized an early program for controlling the pump, which was subsequently improved upon in Cases 4-12. Nevertheless, though the fit with the idealized signal is not as good, the actual velocity variations are as realistic for the tsunami-induced flow as in the other cases, and therefore the results will still be presented.

The given equilibrium scour depth is not taken after just one tsunami wave, but after several waves (up to 89) in succession. While a real life tsunami attack would not likely consist of 89 successive waves, there have been reports of a leading wave followed by several trailing waves, and it is therefore relevant to continue the scour process more than just one wave. Furthermore, continuing until equilibrium is reached will reveal whether the authors' physical understanding of the problem is correct. Similar to the suggestion in the numerical study by Larsen et al. (2017), the authors argue that the scour process resembles that within a steady current scour, with the equilibrium scour depth tending to the steady current scour depth limit after taking into account the finite wave boundary layer thickness.

\section{Hydrodynamic and morphological similitude}

Before continuing to the experimental results, considerations regarding the hydrodynamic and morphological similitude to full scale conditions will be presented. The scaling utilized follows the approach presented in Larsen et al. (2017). It is not possible to achieve complete similarity. However, as shown by Roulund et al. (2005), if the Froude number is $\mathrm{O}(0.2)$ then the effects of the free-surface become negligible, and the scour process can be viewed entirely from a boundary layer perspective. In this case, tsunami induced scour can be studied using a time varying current. In the present study the experimental cases had $F r=0.20-0.31$ and the full scale cases, which are derived in what follows, have $F r=0.14-0.21$, i.e. both in experiments and full scale equivalents the Froude numbers are $\mathrm{O}(0.2)$, hence the effects of the free-surface can be considered small.

Kinematic similarity, and thus geometric similarity, for the scour process is achieved by similarity in $U_{m}^{2} /(g D)$ and $\delta / D$. Similarity in $U_{m}^{2} /(g D)$ ensures that the adverse pressure gradient induced by the presence of the structure itself will be similar at both model and field scales, i.e. that the ratio of the excess stagnation pressure head in front of the monopile $U_{m}^{2} /(2 g)$-topile diameter $D$ will be maintained.

The main driver of the scour process is the horseshoe vortex, whose size and strength is largely determined by the boundary layer thickness-to-diameter ratio $\delta / D$ and the adverse pressure gradient. Achieving similarity in both $U_{m}^{2} /(g D)$ and $\delta / D$ is therefore of utmost importance from the scour perspective. As the boundary layer thickness is governed by the amplitude of the orbital motion, $a$, and thus the period of the motion, then 

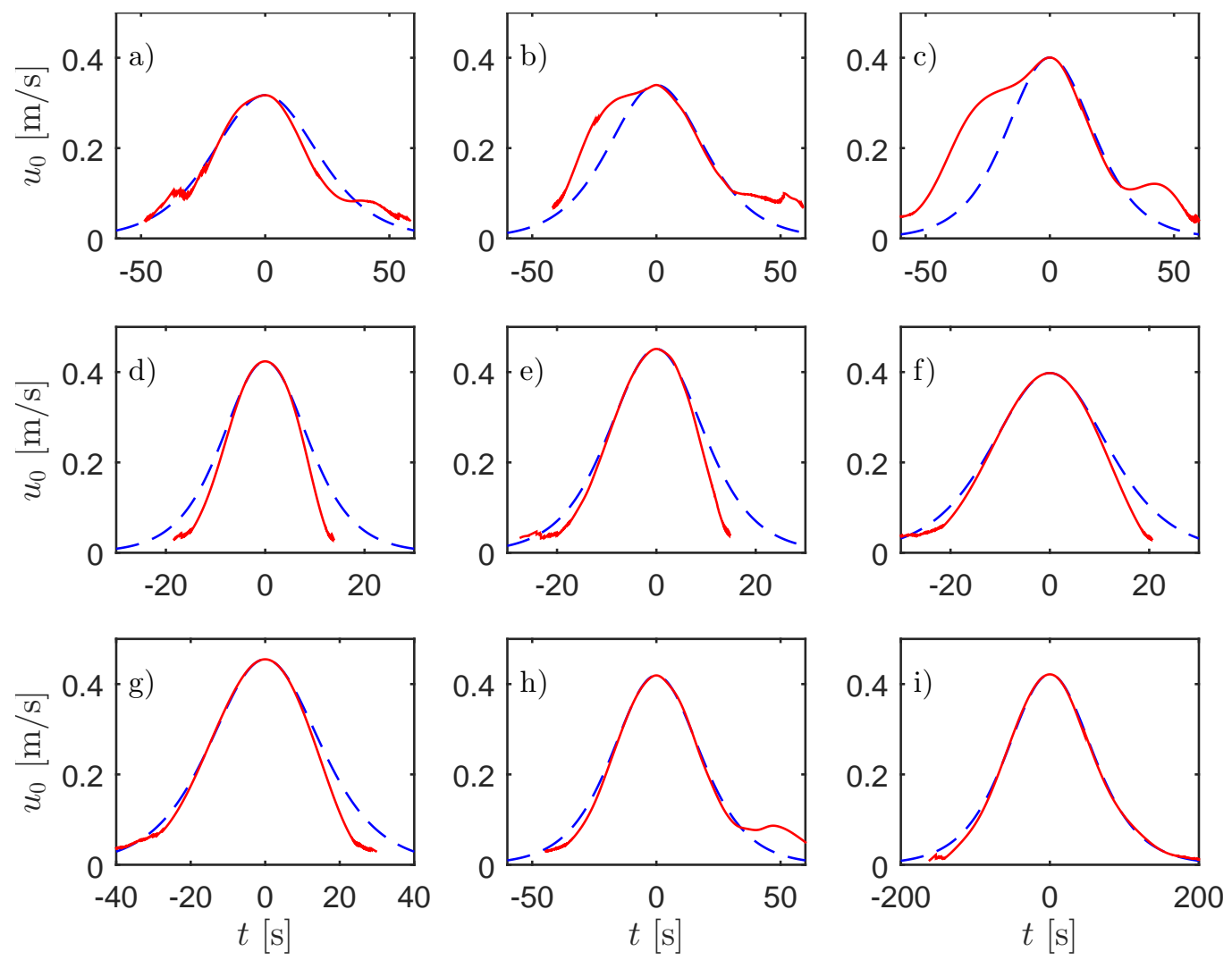

Figure 5: Comparison between measured (-) and fitted (- -) velocity signals for a) Case 1, b) Case2, c) Case 3, d) Case 4, e) Case 5, f) Case 6, g) Case 7, h) Case 8, i) Case 9 .

similarity in boundary layer thickness-to-monopile diameter ratio determines the scaling of the flow period. The above approach ensures the best possible similarity in the hydrodynamics inducing the scour process. Furthermore, to ensure reasonable similarity in the scouring rate relative to the period, the sediment grain size at full scale is chosen to give scour time scale-to-period ratios that are of the same order of magnitude at both model and field scale. To calculate the time scale, the modified time scale for steady current scour presented in Larsen et al. (2017), is utilized:

$$
T_{s}^{*}=\frac{\sqrt{g(s-1) d^{3}}}{D^{2}} T_{s}=\frac{1}{400}\left(\frac{\delta}{D}\right)^{0.7} \theta^{-1.5}
$$

where $T_{s}^{*}$ is the non-dimensional scour time scale, $T_{s}$ is the dimensional scour time scale $\delta$ is the wave boundary layer thickness and $\theta$ is found via equations (4)-(7). The actual time scale of the tsunami-induced scour will be somewhat larger, as the flow is only near maximum for a fraction of the period, but keeping the time scale-to-period ratio approximately the same at both model and full scale will ensure that the morphological time is similar at model and full scale.

At full scale a monopile diameter of $D_{\text {full }}=4 \mathrm{~m}$, a water depth of $h_{\text {full }}=20 \mathrm{~m}$ and a grain size of $d_{\text {full }}=0.3 \mathrm{~mm}$ can be considered typical of conditions at offshore wind turbines. The resulting full scale maximum free-stream velocity is obtained through similarity in $U_{m}^{2} /(g D)$. The corresponding full scale period is then found by achieving simlarity in $\delta / D$ by the use of equation (3). Finally the full-scale wave height has been found from linear shallow water theory:

$$
U_{m}=\frac{H}{2} \sqrt{\frac{g}{h}}
$$

The resulting full scale wave parameters are shown in in Table 2. As seen from Table 2, the cases considered are representative of full scale tsunamis having periods ranging from about $10 \mathrm{~min}$ up to $40 \mathrm{~min}$ and wave heights of 5-8 $\mathrm{m}$ at a water depth of $20 \mathrm{~m}$. The full-scale Shields parameter, $\theta$, is of course significantly larger than the model scale $\theta$, but as mentioned, with scour time scale-to-period ratio similar at both model and full scales, the non-dimensional scour depth should be similar during the scour process. It is again emphasized that the above scaling procedure does not follow standard Froude scaling, but is made to ensure best possible similarity between model and field scale in relation to flow inducing the scour process.

\section{Tsunami-induced boundary layers}

In this section the tsunami-induced boundary layers will be shown and discussed. To accurately predict sediment transport, morphology and scour processes a detailed understanding of the boundary layer is essential. Due to their long yet unsteady and transient nature, tsunami scale boundary layers are difficult to produce experimentally, and as a result 
Table 2: Corresponding full scale wave parameters for the nine (1-9) scour cases and three (10-12) velocity profile cases.

\begin{tabular}{cccccccc}
\hline Case & $T[\mathrm{~s}]$ & $U_{m}[\mathrm{~m} / \mathrm{s}]$ & $H[\mathrm{~m}]$ & $\mathrm{D}[\mathrm{m}]$ & $\mathrm{d}[\mathrm{mm}]$ & $\mathrm{h}[\mathrm{m}]$ & $\theta_{m}$ \\
\hline 1 & 1528 & 2.02 & 5.8 & 4 & 0.3 & 20 & 0.99 \\
2 & 1372 & 2.15 & 6.1 & 4 & 0.3 & 20 & 1.12 \\
3 & 1240 & 2.53 & 7.2 & 4 & 0.3 & 20 & 1.54 \\
\hline 4 & 592 & 2.63 & 7.5 & 4 & 0.3 & 20 & 1.80 \\
5 & 650 & 2.85 & 8.1 & 4 & 0.3 & 20 & 2.07 \\
6 & 809 & 2.52 & 7.2 & 4 & 0.3 & 20 & 1.60 \\
7 & 1032 & 2.87 & 8.1 & 4 & 0.3 & 20 & 2.00 \\
8 & 1247 & 2.66 & 7.6 & 4 & 0.3 & 20 & 1.69 \\
9 & 2416 & 2.66 & 7.6 & 4 & 0.3 & 20 & 1.59 \\
\hline 10 & 648 & 3.10 & 8.85 & 4 & 0.3 & 20 & 2.43 \\
11 & 1028 & 3.23 & 9.21 & 4 & 0.3 & 20 & 2.50 \\
12 & 2071 & 3.10 & 8.85 & 4 & 0.3 & 20 & 2.16
\end{tabular}

tsunami scale boundary layers have received relatively little attention in the literature. Williams and Fuhrman (2016) investigated full scale tsunami induced boundary layers utilizing a numerical one-dimensional vertical (1DV) Reynolds-Averaged Navier-Stokes (RANS) model coupled with $k-\omega$ turbulence closure. Their simulations suggested that the boundary layer of a tsunami will typically not be limited by the water depth at locations sufficiently offshore, and this in turn means that the tsunami-generated boundary layer flow can be considered as both current-like due to their long duration and wave-like due to their unsteady boundary layers which do not necessarily span the entire water column. To show that this is also the case in the present experiments the velocity profiles were measured for three different velocity signals (Cases 10-12). Figure 6 shows the velocity profile at the peak $(\mathrm{t}=0)$. Included in the figure is also the velocity profiled obtained by simulating the flow with the MatRANS model utilized in Williams and Fuhrman (2016), as well as the boundary layer thickness obtained from equation (2). For more details of the model, the reader is referred to Williams and Fuhrman (2016) and Fuhrman et al. (2013) which contains the original description of the model. Figure 6 illustrates that the boundary layer of the experimental tsunami signal does indeed not necessarily span the entire water depth, as seen in Cases 10 and 11. In contrast, in Case 12, the boundary layer extends all the way to the surface, but it should be noted that the period in this case is also extremely long compared to the two other cases. Thus, this tsunami is more current-like than wavelike by the time peak flow is reached. The calculated boundary layer thickness is actually larger than the flow depth, and hence we instead use $\delta=h$ for this case. Furthermore, Figure 6 also illustrates that the MatRANS model captures the behaviour of the transient boundary layer quite well, as a generally excellent match in the predicted velocity profiles is achieved. Finally, and naturally taking into account the good match with the MatRANS model, the predicted boundary layer thickness based on equation (2) also yields a good estimate.

Based on the three measured boundary layers, the previously estimated Shields parameters, which together with the boundary layer thickness, is the governing parameter for the scour depth, can also be compared to the experiments. This is done utilizing the measured velocity closest to the bed to estimate $U_{f m}$, which then can be converted into a Shields parameter uti-
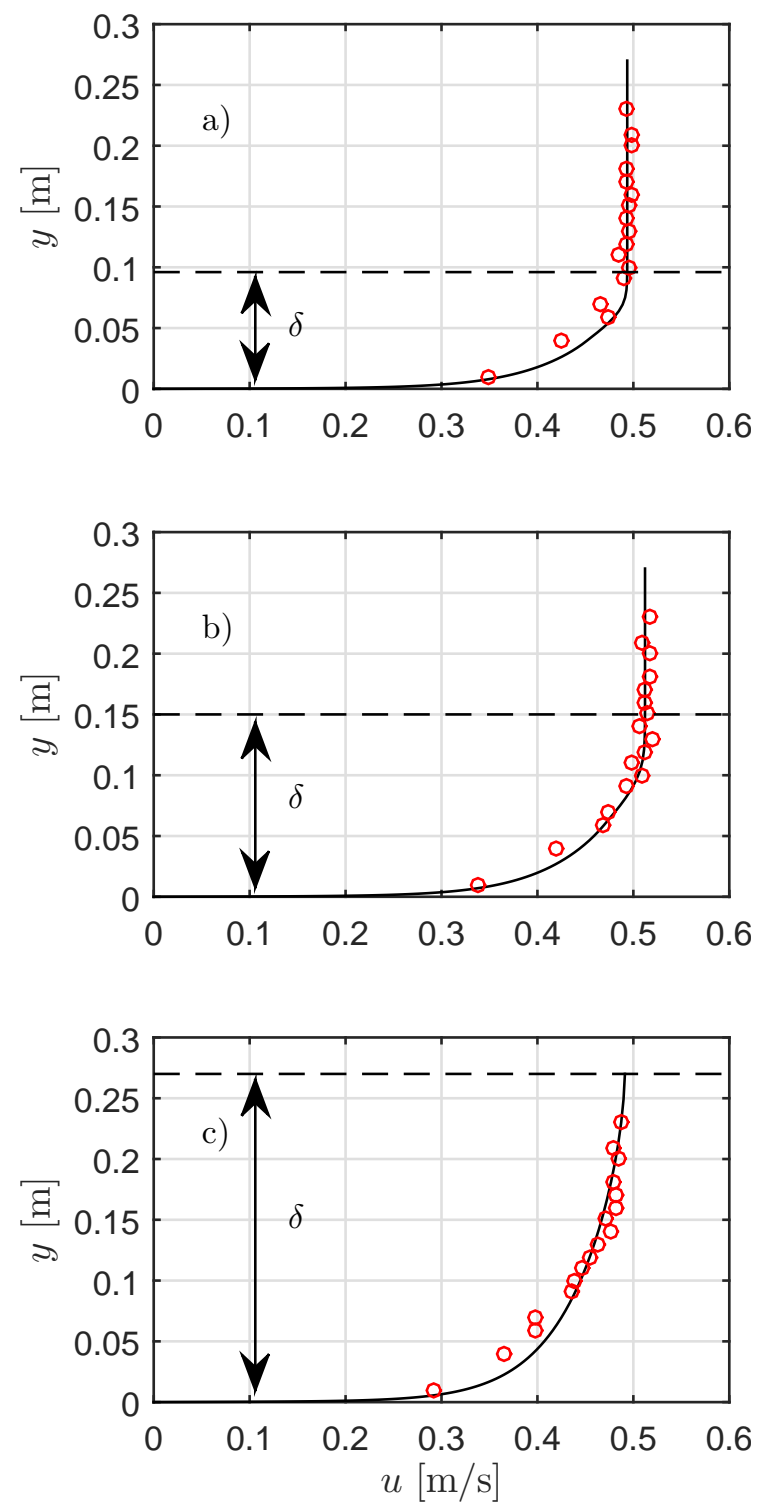

Figure 6: Measured ensemble average velocity profiles at peak flow $(\mathrm{t}=0)$ (o) together with the model results using MatRANS (-) and the boundary layer thickness from (2) (- -) . a) Case 10, b) Case 11 and c) Case 12. 


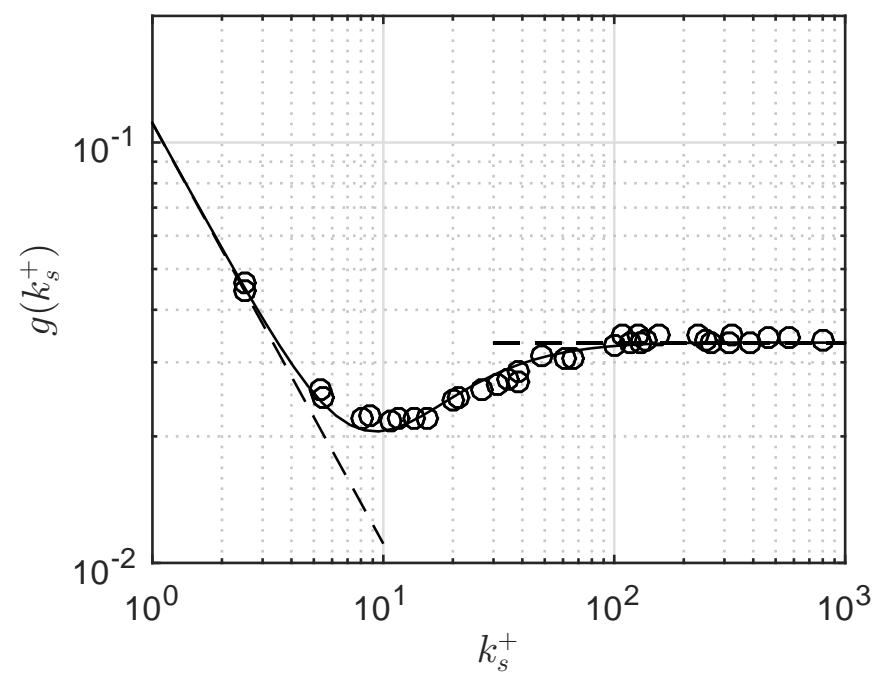

Figure 7: Comparison of equation (11)(-), data (o) Nikuradse (1933) reproduced from Monin and Yaglom (1973) as well as smooth (12) and rough (13) expressions from Monin and Yaglom (1973) (- -).

lizing equation (4). $U_{f m}$ is found by assuming a profile of the following form

$$
U_{m}=\frac{1}{\kappa} U_{f m} \ln \frac{y_{0}}{k_{s} g\left(k_{s}^{+}\right)}
$$

where $y_{0}=0.01 \mathrm{~m}$ is the measurement point closest to the bed, $\kappa=0.4$ is the von Karman constant and

$$
g\left(k_{s}^{+}\right)=\frac{1}{9 k_{s}^{+}}+\frac{1}{30} \exp \left(-140\left(k_{s}^{+}+6\right)^{-1.7}\right)
$$

to take into account that the wall is transitional. The proposed function for $g\left(k_{s}^{+}\right)$above comes from an approximation which has been fit to data from Nikuradse (1933) and joins the smooth (12) and rough (13) expressions given in Monin and Yaglom (1973).

$$
\begin{gathered}
g\left(k_{s}^{+}\right)=\frac{1}{9 k_{s}^{+}} \\
g\left(k_{s}^{+}\right)=\frac{1}{30}
\end{gathered}
$$

The data and the fit to the data is shown in Figure 7. The shape of the function looks very similar to that found in Schlichting and Gersten (2003), originally taken from Tani (1988). From equation (10) $U_{f m}$ is found iteratively and inserted into equation (4) to give $\theta=[0.14,0.13,0.1]$ for Case 10,11 and 12, respectively. It can be seen that the Shields parameters calculated based on the experiments are very similar to those obtained utilizing the friction factor given in (6), see Table 1 (Case 10-12). Thus, it can be concluded that the estimates for both boundary layer thicknesses as well as Shields parameters presented in Table 1 are indeed representative of the experiments and suitable for further scour predictions.

\section{Tsunami-induced scour}

In this section the tsunami-induced scour will be presented. First, the short term scour development will be presented, followed by a presentation of the long term scour development as well as equilibrium scour depths and profiles. After this the results of the predictive engineering model proposed by Larsen et al. (2017) will be compared to the experimental results.

Figure 8 shows the observed temporal scour variation during the first five periods in front of and at the front-side of the monopile for the six of the nine cases (the only six that recorded the detailed scour process). The front-side of the monopile is located approximately $30^{\circ}$ from the center-line and will for the rest of the present paper be referred to as the side.

The scour hole is seen to deepen in a stepwise-cumulative way, with the majority of the scouring happening in the few first periods. The actual scouring is limited to a small fraction of the period. This is very similar to the computed results shown in Larsen et al. (2017). It can also be seen that in all the cases, the scour rate at the side of the monopile is faster than the scour rate at the front. This is interpreted as the bending of the streamlines creating large amplification of the bed shear stress at the front side of the monopile. This is very similar to that observed in experiments by Hjorth (1975) and the numerical study by Baykal et al. (2015). After some time the amplification of the bed shear stress at the sides reduces and the main driver of the scour process is no longer the contracted streamlines, but the horseshoe vortex, which evens out the difference in scour depth at the front and the front side of the monopile (this is even more evident in Figure 9 where the entire scour development is shown, spanning up to nearly 60 events in succession). Some backfilling at the front sides can be observed, most noticeably in Case 4, 5 and 7 (Figure 8a, 8b and 8d). The backfilling occurs at three different instances of the scour process, and it will now be explained for each. First, just before continued scouring a small decrease in scour depth can be seen, most evident in Case 7 (Figure 8d), but also present in Case 6, 8 and 9 (Figure $8 \mathrm{c}, 8 \mathrm{e}$, and $8 \mathrm{f}$ ). From qualitative assessment of the video sequence it can be seen that the backfilling occurs because sand is sliding into the hole. This can be interpreted as the horseshoe vortex not yet attaining its full size, but the free-stream Shields parameter exceeding its critical value. When this happens sand is starting to move, and once it reaches the scour hole, where the bottom slope is at the angle of repose, it slides into the hole. Second, right after scouring a decrease in scour depth can also be seen, most noticeable in Case 4 (Figure 8a), but also present to a lesser degree in Cases 5-9 (Figure 8b-f). In this case, also based on qualitative assessment of the video, sand is likewise sliding into the scour hole, and the physical interpretation is the same, namely that the horseshoe vortex has weakened and the critical shields parameter is still exceeded outside the scour hole, pushing sand into the hole. Third, a discontinuous jump in the scour depth can be seen in-between periods. This is most evident in Case 5 (Figure 8b) at $t / T=1,2,3,4$. The reason for this is reflected flow in the flume transporting some sand from the back of the monopile to the front. The jump is discontinuous in the figure because the reflection occurs after the 

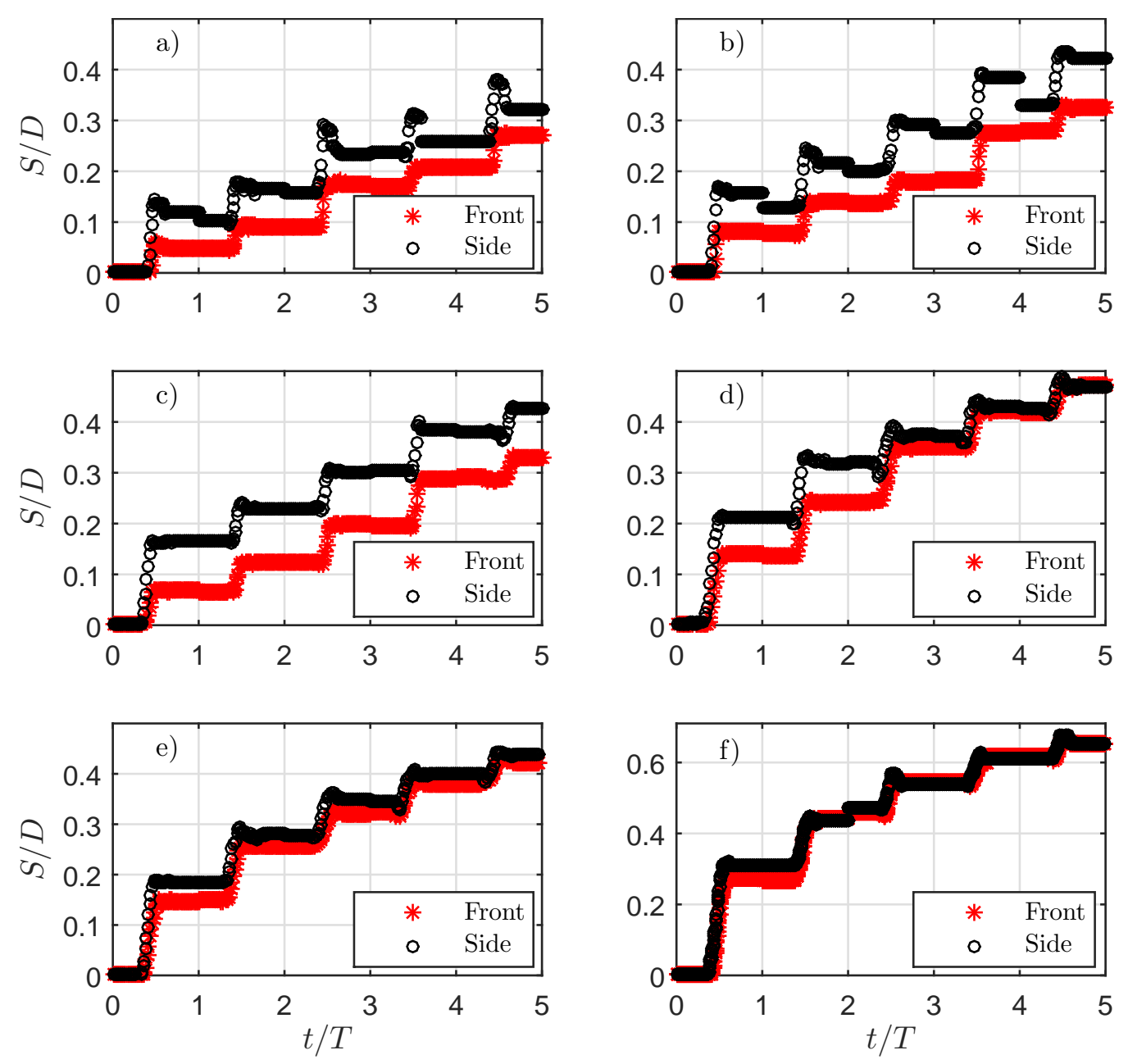

Figure 8: Temporal scour development of the first five periods. a) Case 4, b) Case 5, c) Case 6, d) Case 7, e) Case 8, f) Case 9.

duration of a full period. However, in most cases the backfilling from the reflected flow was rather limited, and does not seem to affect the overall scouring process too much, except perhaps slowing it down a bit compared to the case without reflection. The stepwise cumulative scouring shown in Figure 9 is very similar to Series C from Link et al. (2017) (see their Figure 4c), although their experiments were conducted solely in the clearwater regime.

To further shed light on the physics of the process and also to investigate the possible effects of tsunami scouring in the case of a pre-existing scour hole, the experiments were continued beyond the first five periods until equilibrium or almost equilibrium scour depth was reached. Here we define equilibrium scour depth as a depth that does not change over time. In reality small changes occur with minor scouring and backfilling, but the mean scour depth over a period of time should remain constant. Figure 9 shows the temporal development in the scour depth, with measurements being taken once per period. It can be seen that the depth of the scour holes are increasing rapidly during the first few periods, and thereafter the increase gets slower and slower, and the scour depth is gradually approaching an equilibrium value. It is recognized that final equilibria have not been reached in Case 4, Case 7 and Case 9. Based on the very limited change from period to period in these cases, the scour depths are, however, not expected to increase much beyond what is shown in Figure 9. Again, it can also be seen that the scour depth is increasing faster at the front side of the monopile compared to the front center in the first periods. However, after sufficient time the scour depth at the front side and the front center are more or less equal.

Figure 10 shows the final bed topography of all nine tsunami cases (Figure 10a-i) as well as the final bed from the live-bed steady current experiment (Figure 10j). The bed topography from the nine tsunami cases look rather similar, with a semicircular hole forming around the monopile, and sand deposited behind the monopile. The upstream bed of Cases 1 and 2 (Figure 10a and 10b) are clear of bed forms and could thus be interpreted as being in the clear-water regime. All cases are in the clear-water regime in parts of the periods, but the live-bed regime period is generally long enough to develop bed forms. The cases with bed forms bear some resemblance to the steady current scour hole (Figure 10j) although the extend of the hole in the steady current case is somewhat larger. This is probably due to (1) the tsunami cases perhaps not reaching full equilibrium, and probably more importantly, due to (2) the boundary layer thickness not spanning the entire depth in the tsunami 

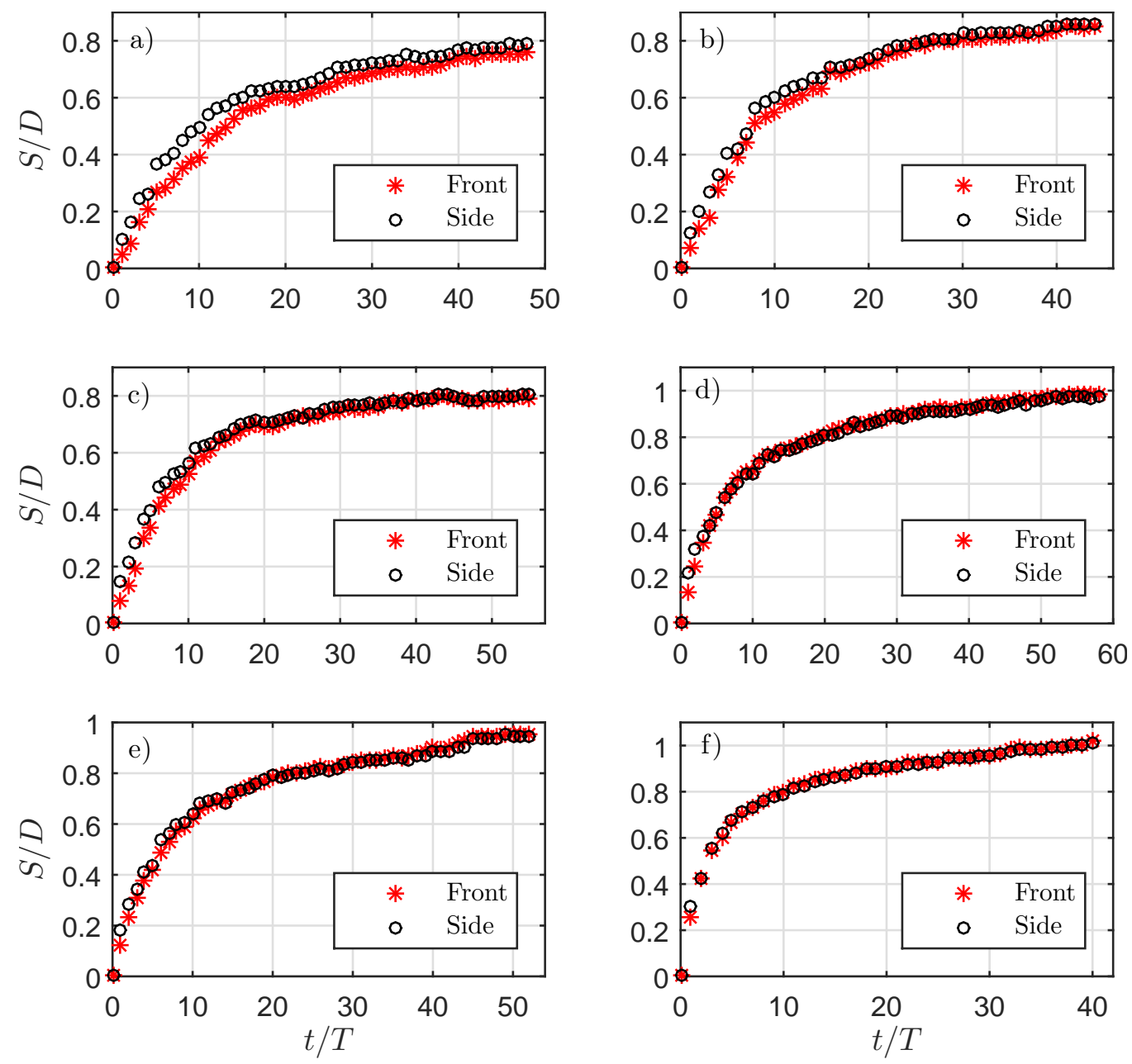

Figure 9: Temporal scour development of the entire experiment at integer values of $t / T$ (i.e. after each tsunami). a) Case 4, b) Case 5, c) Case 6, d) Case 7 , e) Case 8, f) Case 9.

flows, which will limit the relative size of the horseshoe vortex.

In Larsen et al. (2017) it was argued that the tsunami-induced scour depth, should (if given enough time) tend to the currentinduced equilibrium scour depth, after taking into account the finite boundary layer thickness, and that this could be predicted utilizing

$$
\frac{S_{e}}{S_{0}}=1-\exp \left(-0.9 \frac{\delta}{D}\right)
$$

where $S_{0} / D=1.3$ is the widely-accepted equilibrium current induced scour value around a circular pile (without depth limitation). In Figure 11 the equilibrium scour depths are shown as a function of the boundary layer thickness to diameter ratio and compared to equation (14). The scour depths are not taken from the video, but rather as the maximum depth from the scanned bed. However the estimates from the video do not differ significantly from the bed scan. Included in the figure are also the results from the MSc thesis of Lavictoire (2015) who studied the bore induced scour around a circular cylinder standing on a dry beach, as well as the results for the bore induced scour around a circular cylinder by Shafiei et al. (2015). We have taken the height of the approaching bore as the boundary layer thickness for these latter two studies. It may be seen that the tsunami-induced equilibrium scour depth can reasonably be predicted by equation (14). There is, of course, some scatter, but this scatter is of the same order of magnitude as the scatter of the current induced scour depth, see Larsen et al. (2017) where the relationship in Equation (14) was proposed. It can also be seen that equation (14) provides a good estimate of the equilibrium scour depth in the case where the cylinder is standing in-land and is subjected to a bore, as equation (14) also captures well the experimental results by Lavictoire (2015) and Shafiei et al. (2015).

As seen from Figures 8 and 9 the equilibrium scour depths in the experiments are not reached after one or two tsunami waves, but rather after approximately 50 tsunami waves, and therefore the scour depth predicted from equation (14) may not be appropriate for estimating the scour depth of a tsunami attack. In some cases it will, but this will depend entirely of the time scale of the scour process and the boundary layer thickness. Therefore, the temporal evolution should likewise generally be taken into account. In Larsen et al. (2017) the following expression was suggested for the temporal evolution of the tsunami 

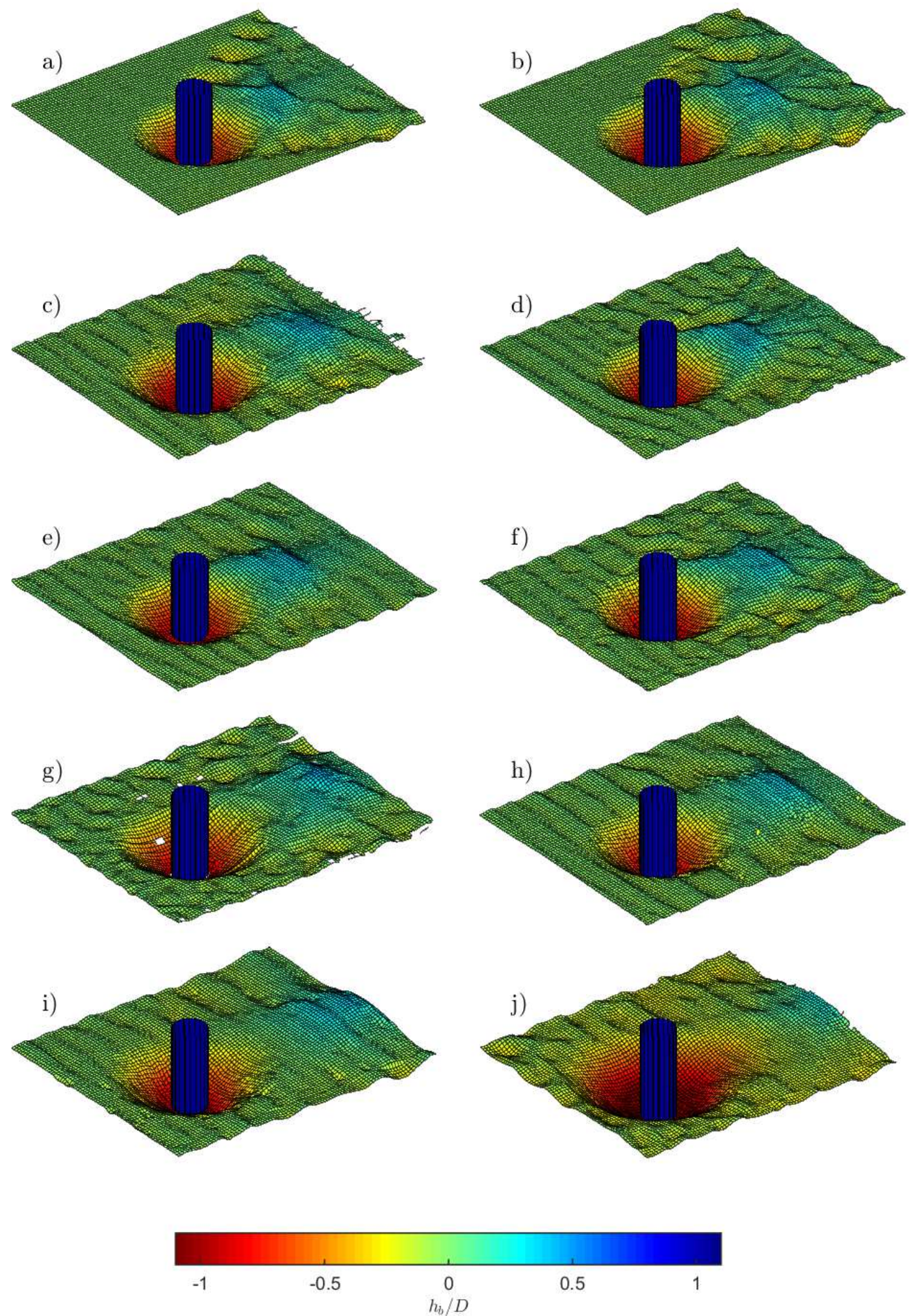

Figure 10: Equilibrium bed profiles of a) Case 1, b) Case 2, c) Case 3, d) Case 4, e) Case 5, f) Case 6, g) Case 7, h) Case 8, i) Case 9, j) Case 13 (Steady scour). 


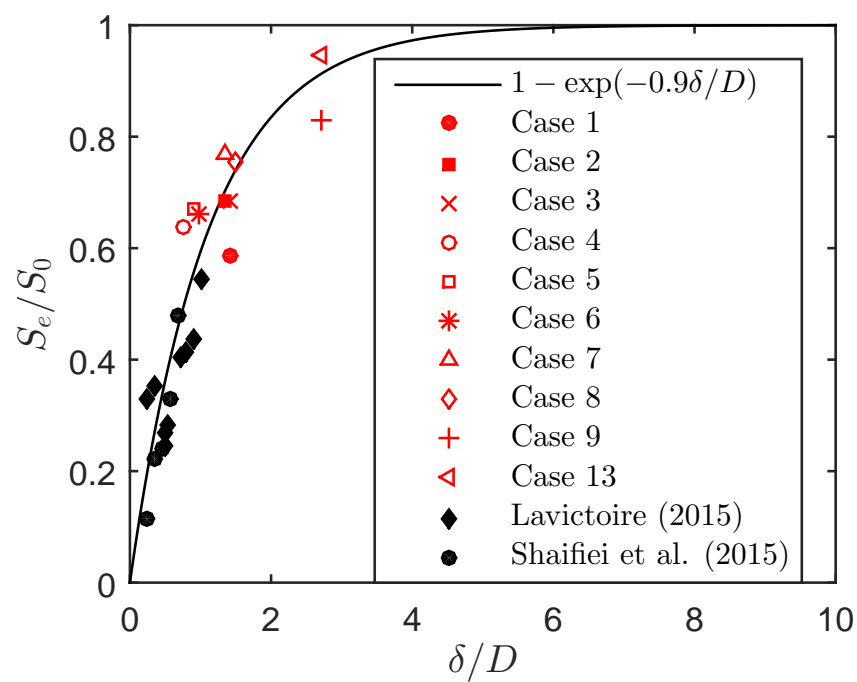

Figure 11: Equilibrium measured scour depth as function of predicted boundary layer thickness.

induced scour depth

$$
\frac{S}{D}=\frac{S_{e}}{D}\left(1-\exp \left(-\frac{t_{s}}{T_{s}}\right)\right), \quad t_{s}=n \psi T .
$$

where $S_{e}$ is the equilibrium scour depth predicted by equation (14). This resembles the commonly used expression to characterize typical time development of scour processes, see Sumer and Fredsøe (2002). In the equation above $t_{s}$ represents the effective scour time, and $n$ represents the integer number of successive waves characterizing a given tsunami i.e. $n=1$ can be utilized to predict the maximum scour occurring during the leading tsunami wave, with $n=2,3, \ldots$ utilized for predicting the accumulated scour induced by any successive waves. The additional factor $\psi \leq 1$ represent the effective scouring fraction of a period. In Larsen et al. (2017) the tsunami was represented by a sinusoidal flow and $\psi=1 / 3$ was chosen. This value is, however, not appropriate for the present situation where the flow is unidirectional. Instead, we have chosen to predict the value by estimating the ratio of the predicted volume of sediment transported by the tsunami wave relative to the predicted volume of sediment transported by a steady current having the same $\theta$ as $\theta_{m}$ of the tsunami, i.e.

$$
\psi=\frac{\int_{0}^{T} \theta\left(\theta>\theta_{c}\right)^{3 / 2} d t}{\int_{0}^{T} \theta_{m}^{3 / 2} d t}
$$

where $\theta$ is the predicted instantaneous value of Shields parameter of the tsunami, $\theta_{c}=0.05$ is the critical Shields parameter, and $\theta_{m}$ is the maximum Shields parameter of the tsunami predicted by equation (4). $\theta$ is calculated by equations (4), (5) and (7), maintaining a constant friction factor but substituting $U_{m}$ with $u_{0}=U_{m} \operatorname{sech}^{2}(\Omega t)$. In the above formulation $\theta$ is raised to $3 / 2$ as many sediment transport formulae scale with $\theta^{3 / 2}$, see e.g. Fredsøe and Deigaard (1992). The resulting values of $\psi$ can be seen in Table 1. It should be noted that equation (16) does not give $\psi=1 / 3$ integrating one half-cycle of the sinusoidal flow from Larsen et al. (2017). However, $\psi$ estimates for these sinusoidal wave signals using equation (16) are not significantly different from $\psi=1 / 3$ hence using equation (16) in this case (only integrating for one half cycle) would still give reasonable scour predictions.

Utilizing the estimated values of $\psi$ the predicted scour evolution of Cases 4-9 are plotted in Figure 12 together with the measured scour depths. As can be seen, the simple predictive model proposed above does a good job of predicting the scour observed within the experiments, especially during the first tsunami waves. Further taking into account the scatter in the experimental results leading to equation (14) (on which the engineering model is built), the estimate is satisfactory. The worst prediction is Case 9 where the predicted scour depth is approximately $20 \%$ more than from the experiment, but still well within normal scatter in scour experiments.

\section{Model-experiment comparison}

In this section Cases 6-8 will be simulated with the same model used in the previous numerical study by Larsen et al. (2017) on tsunami induced scour around monopile foundations where the tsunami was there represented by a sinusoidal velocity signal. This is done to strengthen the validity of the simple predictive engineering model. In Larsen et al. (2017) the engineering model was suggested based purely on numerical results, and a good comparison with the current experiments will further validate the accuracy of the numerical model and thus also the predictive engineering model for tsunamis represented, not only as single waves, but also as sinusoidal waves.

The simulations are performed using the sediMorph model, implemented in OpenFOAM-1.6-ext, originally developed by Jacobsen (2011) and Jacobsen et al. (2014). The model is a fully coupled RANS model, with $k-\omega$ turbulence closure, bed load transport, suspended load transport and morphology. The model is very well validated and has been used to simulate breaker bar development by Jacobsen et al. (2014), current, wave and wave-plus-current induced scour and backfilling beneath submarine pipelines by Fuhrman et al. (2014), Larsen et al. (2016) and Bayraktar et al. (2016) as well as current, wave and tsunami induced scour around a monopile by Baykal et al. (2015), Baykal et al. (2017) and Larsen et al. (2017). For more details on the model implementation the reader is referred to Jacobsen et al. (2014).

The computational domain is discretized into finite volumes of quadrilateral blocks in varying shapes and dimensions and the computational domain has the following dimensions: length, $l=20 D$, width, $w=15 D$, and height, $h=2 D$, in which $D$ is the monopile diameter. The total number of cells comprising the computational domains utilized is 170,496 with the near-bed cells having a height $O(d)$, in which $d$ is the grain size. The monopile is located at the center of the domain $(x, y)=(0,0)$. This mesh and boundary conditions are exactly the same as used in Larsen et al. (2017) who simulated steady current induced scour as well as tsunami induced scour and the reader is referred to this study for more details of the model set-up. Figure 13 shows the detailed scour development of Cases 6-8 of both the experiment and the numerical model. It 

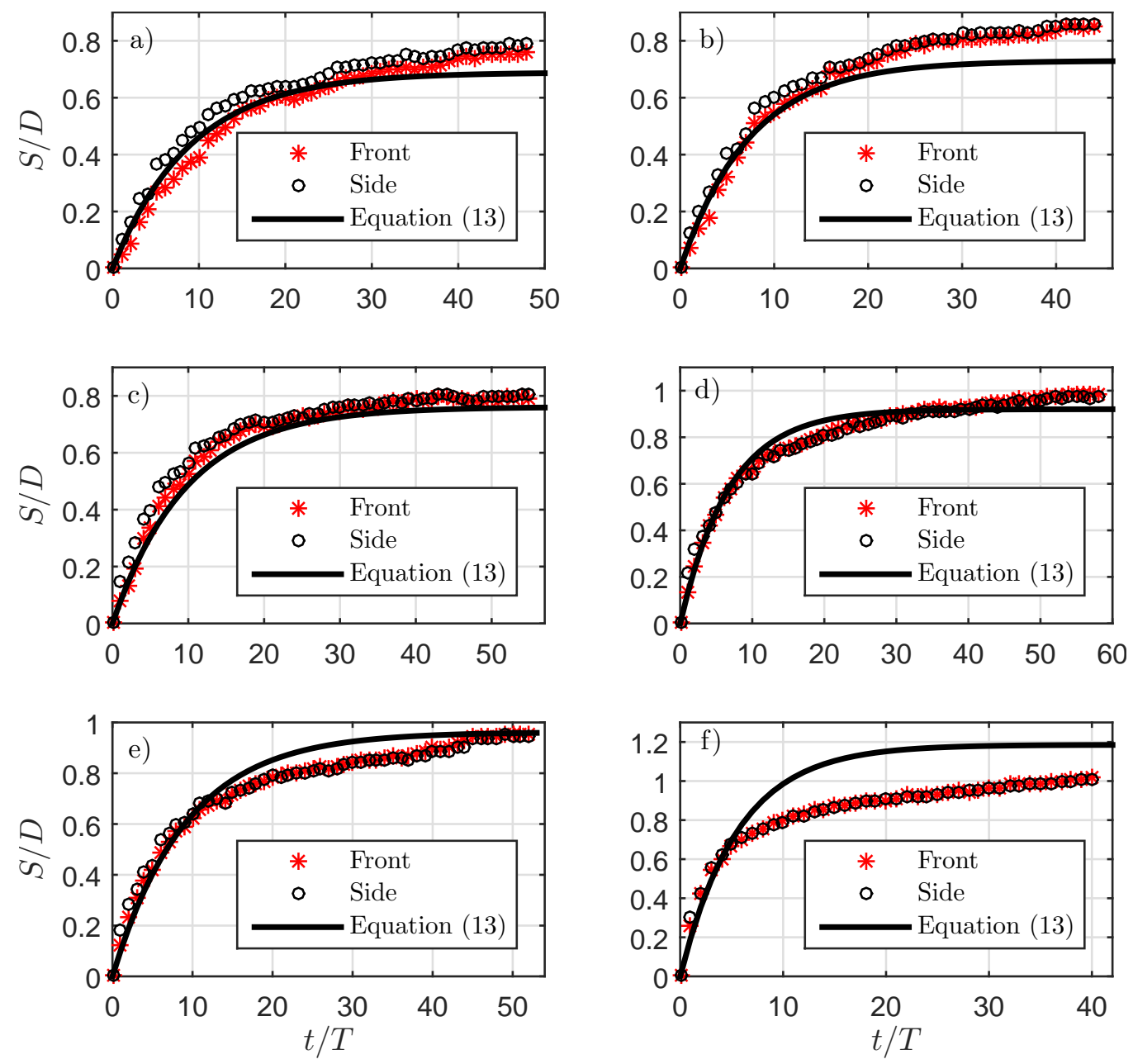

Figure 12: Predicted and measured temporal scour development of the entire experiment. a) Case 4, b) Case 5, c) Case 6, d) Case 7, e) Case 8, f) Case 9.

can be seen that the model, similar to the experiments, predicts the scour occurring in a stepwise fashion, with the scour rate at the side being slightly larger than the center. The model overpredicts the scour in the first period, but after that the agreement between the model and the experiments improves. The reason for the over-predicted scour depth in the first period could be that all sediment transport formulae within the model build on the assumption of rough-turbulent flow at the bed. In reality the grain Reynolds number $U_{f} d / v \approx 3$. In this region the critical Shields parameter $\theta_{c}$ is slightly larger than $\theta_{c}=0.05$ which is utilized in the model. Another explanation could be that even though the bed was levelled between each experiment, it was not completely flat, as in the simulation. Small bed forms could thus give extra flow resistance and thus lower the bed shear stress compared to the model. After simulating a few waves the modelled cases also contain some bed forms, and the scour development is more similar. The gradual development of bed forms can also be seen in Figure 14 where the simulated bed profile of Case 7 is shown after one, three and five periods. After one period the bed is almost free of bed forms. After three periods small ripples have developed on the side and finally after five periods the bed forms have spread to the front of the monopile. The gradual deepening and widening of the scour hole in time is also quite clear, and the bed profile after five periods is starting to show resemblance with the equilibrium profile of Case 7 (Figure 10h).

Despite the difference between the initial scour depths of the model and the experiment, we still find this comparison satisfactory. This further validates the sediMorph model as well as the predictive engineering formula for tsunami induced scour beneath sinusoidally varying velocity signals.

\section{Conclusions}

This paper presents an experimental analysis of tsunamiinduced scour around monopiles representative of offshore wind turbine foundations. The offshore scour process has been studied by treating the incoming tsunami as a time varying current which enabled properly scaled experiments. To complement a previous (entirely numerical) study by Larsen et al. (2017) using a sinusoidal velocity signal, a "single wave" (elongated soliton) formulation has been used as a synthetic tsunami signal, which has been repeated in succession.

Based on a recently developed method for maintaining similarity between model and full scale tsunami-induced scour it is shown that the nine cases considered corresponds to real-life 

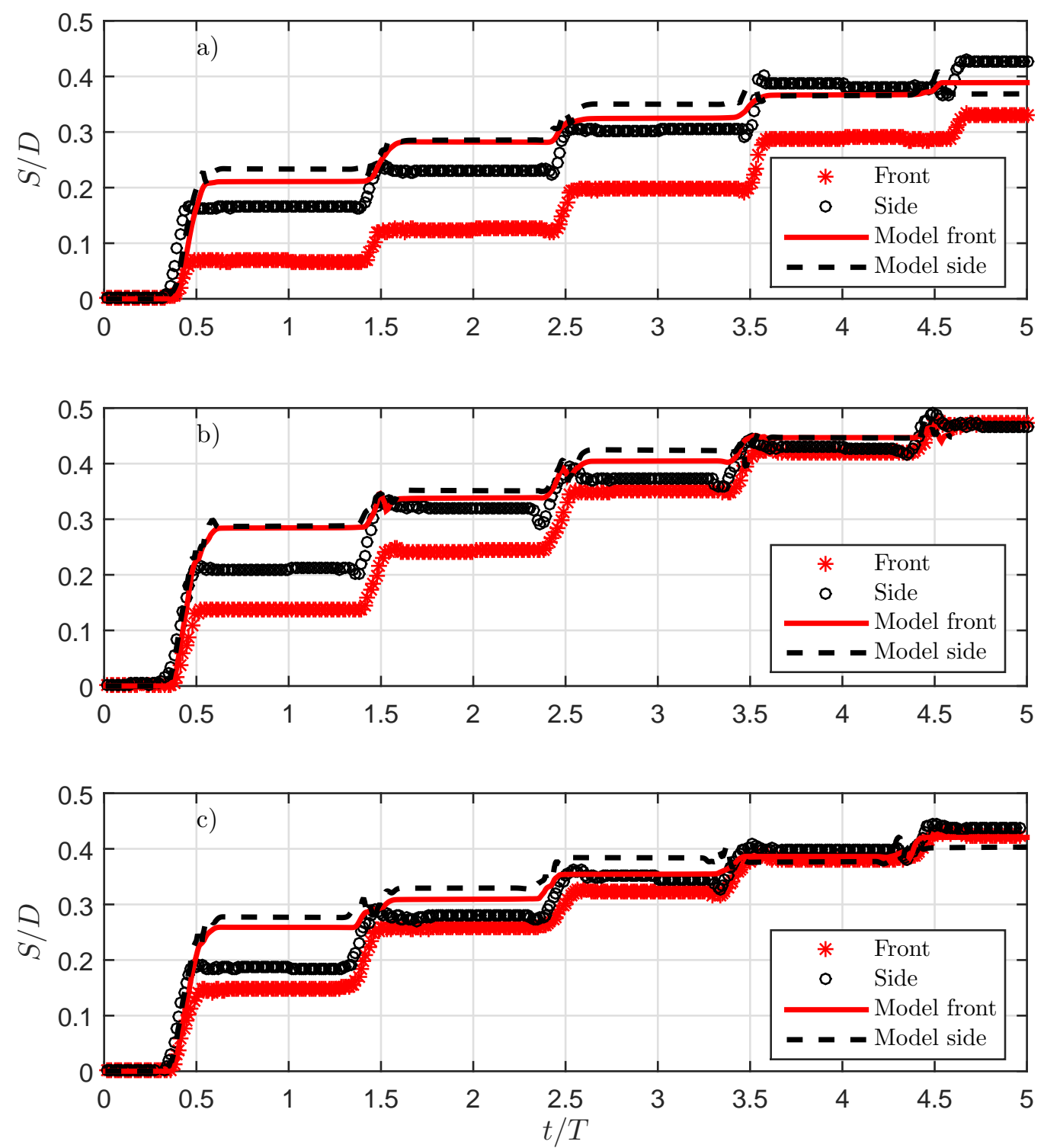

Figure 13: Comparison between modelled and experimental scour development.

tsunamis having periods from 10 minutes to 40 minutes and wave heights of $5 \mathrm{~m}$ to $8 \mathrm{~m}$ at a water depth of $20 \mathrm{~m}$. The boundary layer beneath the model tsunami signal is shown to be accurately predicted by the MatRANS model (Fuhrman et al. (2013)) as well as by recently developed formula for boundary layer thickness and friction factors beneath tsunami waves (Williams and Fuhrman (2016)).

The scour development is shown to occur in a stepwise cumulative fashion, with the equilibrium scour depth tending to that predicted by existing steady current scour depth expressions after accounting for the finite boundary layer thickness induced by the unsteady flow.

It is shown that the temporal development can reasonably be predicted by the practical engineering model developed by Larsen et al. (2017) with a small change in the parameter $\psi$ (representing the effective scouring duration within a period), which is now found analytically as the ratio of the volume sediment transported by one tsunami wave relative to volume of sediment transported by a steady current having the same Shields parameter as the maximum Shields parameter of the tsunami. The practical engineering model thus only requires use of existing experimentally-based expressions for predicting steady current scour and time scales as wells as analytical calculations of the parameter $\psi$.

Finally, three cases were simulated by a fully coupled hydrodynamic and morphologic CFD-model and a good correspondence was obtained. These results add to the validation of the sediMorph model (Jacobsen (2011)), and hence give further confidence in the previous purely-numerical study of tsunamiinduced scour conducted by Larsen et al. (2017). 

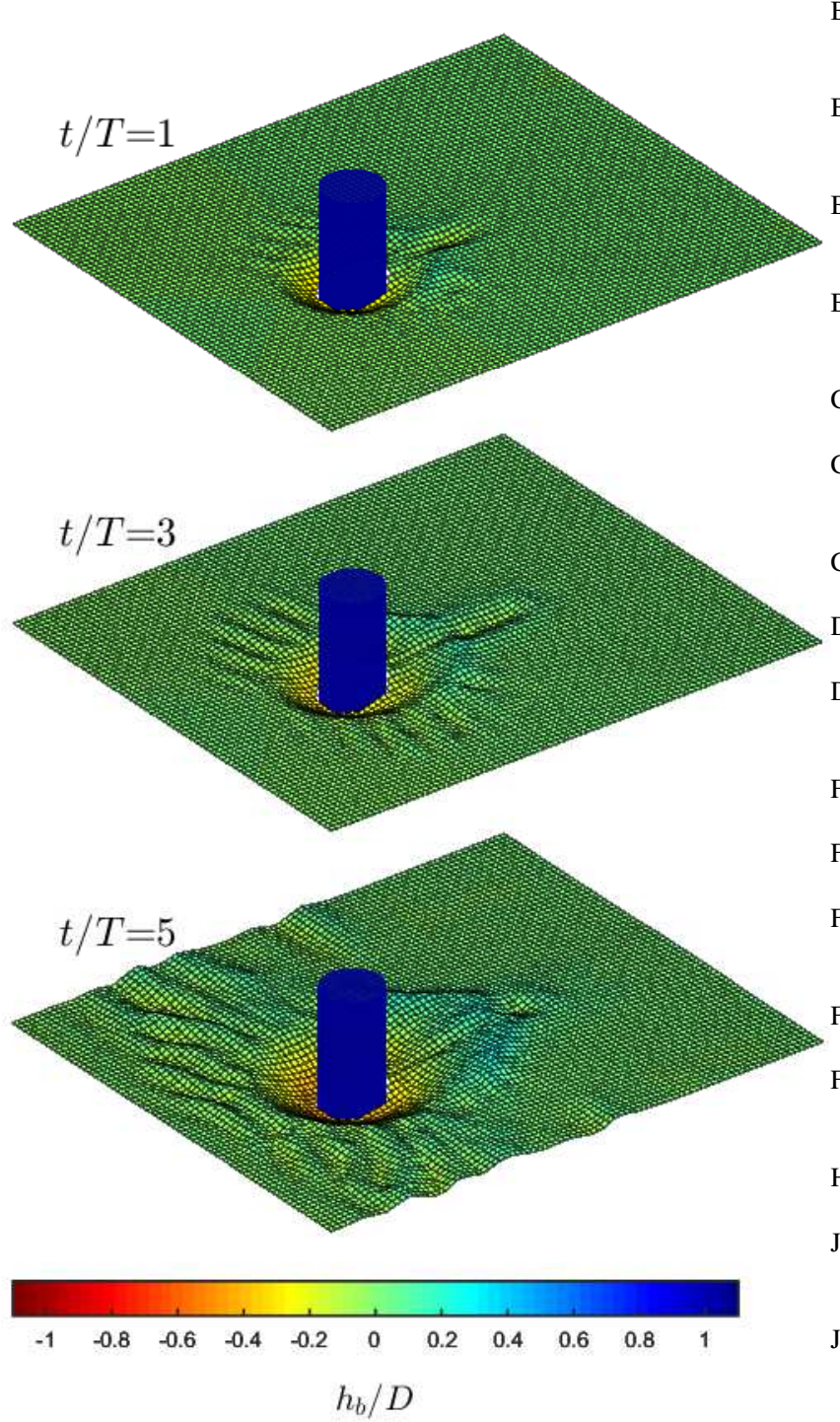

Figure 14: Simulated bed profiles of Case 7 at $t / T=1, t / T=3$ and $t / T=5$.

\section{Acknowledgements}

The first and last author acknowledge support from the European Union project ASTARTE-Assessment, Strategy And Risk Reduction for Tsunamis in Europe, Grant no. 603839 (FP7ENV-2013.6.4-3).

\section{References}

Apotsos, A., Buckley, M., Gelfenbaum, G., Jaffe, B., Vatvani, D., 2011 a. Nearshore tsunami inundation model validation: Toward sediment transport applications. Pure and App. Geophys. 168 (11), 2097-2119.

Apotsos, A., Gelfenbaum, G., Jaffe, B., 2011b. Process-based modeling of tsunami inundation and sediment transport. J. Geophys. Res. 116 (1), - .

Apotsos, A., Gelfenbaum, G., Jaffe, B., Watt, S., Peck, B., Buckley, M., Stevens, A., 2011c. Tsunami inundation and sediment transport in a sediment-limited embayment on American Samoa. Earth-Sci Rev. 107 (12), 1-11.
Baykal, C., Sumer, B. M., Fuhrman, D. R., Jacobsen, N. G., Fredsøe, J., 2015. Numerical investigation of flow and scour around a vertical circular cylinder. Phil. Trans. Roy. Soc. A 373, article no. 20140104.

Baykal, C., Sumer, B. M., Fuhrman, D. R., Jacobsen, N. G., Fredsøe, J., 2017. Numerical simulation of scour and backfilling processes around a circular pile in waves. Coast. Eng. 122, 87-107.

Bayraktar, D., Ahmad, J., Larsen, B. E., Carstensen, S., Fuhrman, D. R., 2016. Experimental and numerical study of wave-induced backfilling beneath submarine pipelines. Coast. Eng. 118, 63-75.

Bricker, J. D., Francis, M., Nakayama, A., 2012. Scour depths near coastal structures due to the 2011 Tohoku tsunami. J. Hydraul. Res. 50 (6), 637 641.

Chan, I.-C., Liu, P. L. F., 2012. On the runup of long waves on a plane beach. J. Geophys. Res. - Oceans 117 (8), 1-17.

Chen, J., Huang, Z., Jiang, C., Deng, B., Long, Y., 2013. Tsunami-induced scour at coastal roadways: a laboratory study. Natural Hazards 69 (1), $655-$ 674.

Cheng, W., Weiss, R., 2013. On sediment extent and runup of tsunami waves. Earth and Planetary Science Letters 362, 305-309.

Dawson, A. G., Shi, S., 2000. Tsunami deposits. Pure and Applied Geophysics 157 (6-8), 875-897.

Douglas, S., Nistor, I., 2015. On the effect of bed condition on the development of tsunami-induced loading on structures using openfoam. Natural Hazards 76 (2), 1335-1356

Fredsøe, J., Deigaard, R., 1992. Mechanics of Coastal Sediment Transport. World Scientific, Singapore.

Fu, L., Kosa, K., Sasaki, T., 2013. Tsunami damage evaluation of Utatsu bridge by video and 2-d simulation analyses. J. Structural Eng. 59a, 428-438.

Fuhrman, D. R., Baykal, C., Sumer, B. M., Jacobsen, N. G., Fredsoe, J., 2014. Numerical simulation of wave-induced scour and backfilling processes beneath submarine pipelines. Coast. Eng. 94, 10-22.

Fuhrman, D. R., Madsen, P. A., 2009. Tsunami generation, propagation, and run-up with a high-order boussinesq model. Coast. Eng. 56 (7), 747-758.

Fuhrman, D. R., Schløer, S., Sterner, J., 2013. RANS-based simulation of turbulent wave boundary layer and sheet-flow sediment transport processes. Coast. Eng. 73, 151-166.

Hjorth, P., 1975. Studies on the nature of local scour. Lund Institute of Technology, University of Lund, Bulletin Series A 46.

Jacobsen, N. G., 2011. A full hydro- and morphodynamic description of breaker bar development. Ph.D. thesis, Technical University of Denmark, Kgs. Lyngby.

Jacobsen, N. G., Fredsøe, J., Jensen, J. H., 2014. Formation and development of a breaker bar under regular waves. Part 1: Model description and hydrodynamics. Coast. Eng. 88, 182-193.

Jayaratne, M. P. R., Premaratne, B., Adewale, A., Mikami, T., Matsuba, S., Shibayama, T., Esteban, M., Nistor, I., 2016. Failure mechanisms and local scour at coastal structures induced by tsunami. C. Eng. Journal 58 (4), 1640017.

Jiang, C., Chen, J., Yao, Y., Liu, J., Deng, Y., 2015. Study on threshold motion of sediment and bedload transport by tsunami waves. Ocean Eng. 100, 97 106.

Kuriyama, Y., Takahashi, K., Yanagishima, S., Tomita, T., 2014. Beach profile change at Hasaki, Japan caused by 5-m-high tsunami due to the 2011 off the Pacific coast of Tohoku earthquake. Mar. Geol. 355, 234-243.

Lacy, J. R., Rubin, D. M., Buscombe, D., 2012. Currents, drag, and sediment transport induced by a tsunami. J. Geophys. Res.- Oceans 117 (9), -

Larsen, B. E., Fuhrman, D. R., Baykal, C., Sumer, B. M., 2017. Tsunamiinduced scour around monopile foundations. Coast. Eng. 129, 36-49.

Larsen, B. E., Fuhrman, D. R., Sumer, B. M., 2016. Simulation of wave-pluscurrent scour beneath submarine pipelines. J. Waterw. Port C-ASCE 142 (5), article no. 08216001

Lavictoire, A., 2015. Bore-Induced Local Scour around a Circular Structure. University of Ottawa. Canada. 2015.

Link, O., Castillo, C., Pizarro, A., Rojas, A., Ettmer, B., Escauriaza, C., Manfreda, S., 2017. A model of bridge pier scour during flood waves. J.1 of Hydraul. Res. 55 (3), 310-323.

Madsen, P. A., Fuhrman, D. R., 2008. Run-up of tsunamis and long waves in terms of surf-similarity. Coast. Eng. 55, 209-223.

Madsen, P. A., Fuhrman, D. R., Schäffer, H. A., 2008. On the solitary wave paradigm for tsunamis. J. Geophys. Res. 113, article no. C12012.

Monin, A., Yaglom, A., 1973. Statistical fluid mechanics: Mechanics of Turbu- 
lence. MIT Press,.

Nakamura, T., Kuramitsu, Y., Mizutani, N., 2008. Tsunami scour around a square structure. Coastal Engineering Journal 50 (2), 209-246.

Nikuradse, J., 1933. Stroemungsgesetze in rauhen rohren. Forschungsheft 4.

Roulund, A., Sumer, B. M., Fredsøe, J., Michelsen, J., 2005. Numerical and experimental investigation of flow and scour around a circular pile. J. Fluid Mech. 534, 351-401.

Schimmels, S., Sriram, V., Didenkulova, I., 2016. Tsunami generation in a large scale experimental facility. Coast. Eng. 110, 32-41.

Schlichting, H., Gersten, K., 2003. Boundary-layer theory. Springer,.

Shafiei, S., Melville, B. W., Shamseldin, A. Y., Watts, M. J. H., Hoffman, T. G., 2015. Experimental investigation of tsunami bore induced scour around structures. Australian Coasts and Ports 2015 Conference, 807-813.

Sriram, V., Didenkulova, I., Sergeeva, A., Schimmels, S., 2016. Tsunami evolution and run-up in a large scale experimental facility. Coast. Eng. 111, 1-12.

Sugawara, D., Goto, K., Jaffe, B. E., 2014a. Numerical models of tsunami sediment transport - current understanding and future directions. Mar. Geol. 352 295-320.

Sugawara, D., Takahashi, T., Imamura, F., 2014b. Sediment transport due to the 2011 Tohoku-Oki tsunami at Sendai: Results from numerical modeling. Mar. Geol. 358, 18-37.

Sumer, B. M., Fredsøe, J., 2002. The Mechanics of Scour in the Marine Environment. World Scientific, Singapore.

Tani, I., 1988. Drag reduction by rible viewed as roughness problem. Proceedings of the Japan Academy Series B-physical and Biological Sciences 64 (2), 21-24.

Tonkin, S., Yeh, H., Kato, F., Sato, S., 2003. Tsunami scour around a cylinder. J. Fluid Mech. 496 (496), 165-192.

Udo, K., Takeda, Y., Tanaka, H., 2016. Coastal morphology change before and after 2011 off the Pacific coast of Tohoku earthquake tsunami at RikuzenTakata coast. Coast. Eng. Journal 58 (4), 1640016.

Wei, Z., Dalrymple, R. A., Rustico, E., Herault, A., Bilotta, G., 2016. Simulation of nearshore tsunami breaking by smoothed particle hydrodynamics method. J. Waterw. Port C-ASCE 142 (4), 05016001.

Williams, I. A., Fuhrman, D. R., 2016. Numerical simulation of tsunami-scale wave boundary layers. Coast. Eng. 110, 17-31.

Wilson, R., Davenport, C., Jaffe, B., 2012. Sediment scour and deposition within harbors in california (usa), caused by the march 11, 2011 tohoku-oki tsunami. Sedimentary Geology 282, 228-240.

Yeh, H., Mason, H. B., 2014. Sediment response to tsunami loading: mechanisms and estimates. Geotechnique 64 (2), 131-143. 